Supporting Information

\title{
A New Morphogenetic Strategy Inspired by the Viscoelasticity of Polymers
}

Jieze Shen, Tingting Chen, Yue Huang, Qiao Jin, Jian Ji*

MOE Key Laboratory of Macromolecule Synthesis and Functionalization of Ministry of Education, Department of Polymer Science and Engineering, Zhejiang University, Hangzhou, 310027, Zhejiang Province, PR China. Fax/Tel: (+86)571-87953729; E-mail address: jijian@zju.edu.cn (J. Ji); 


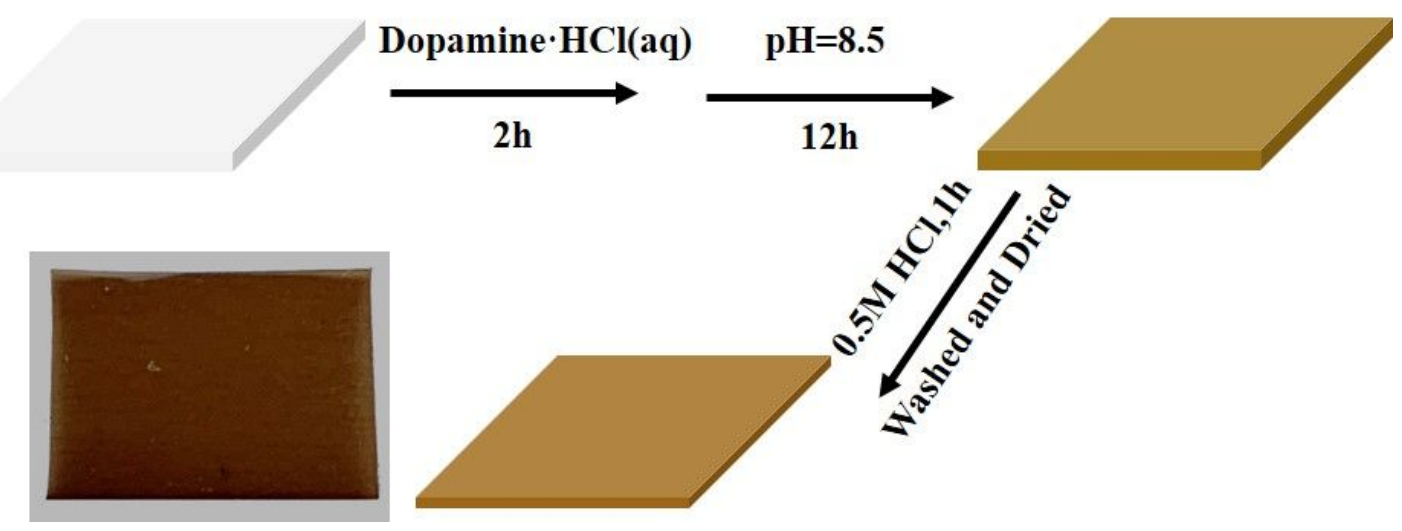

Figure S1. Schematic representation of the PDA-modification of a Nafion film.

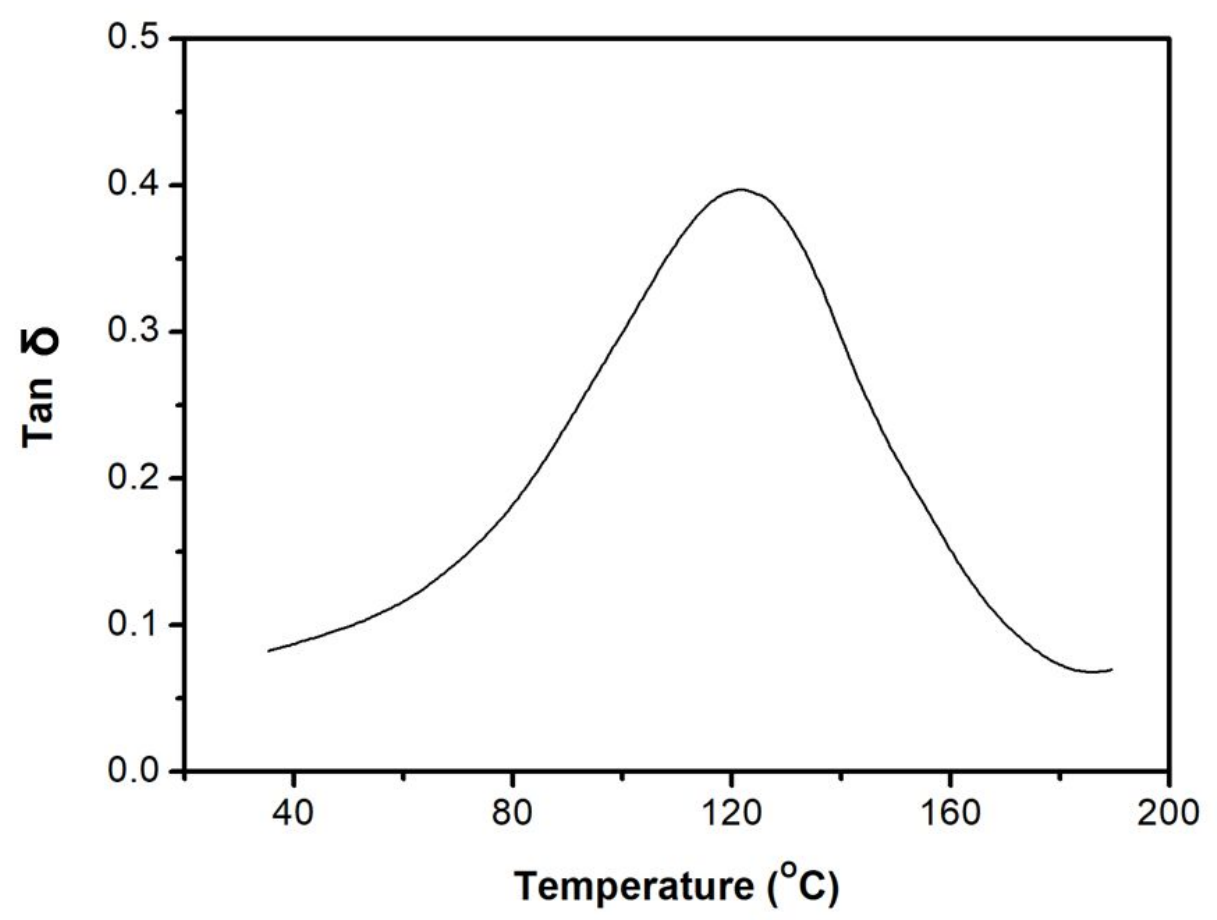

Figure S2. DMA curves of $\tan \delta$ of nascent Nafion/PDA composite films. 


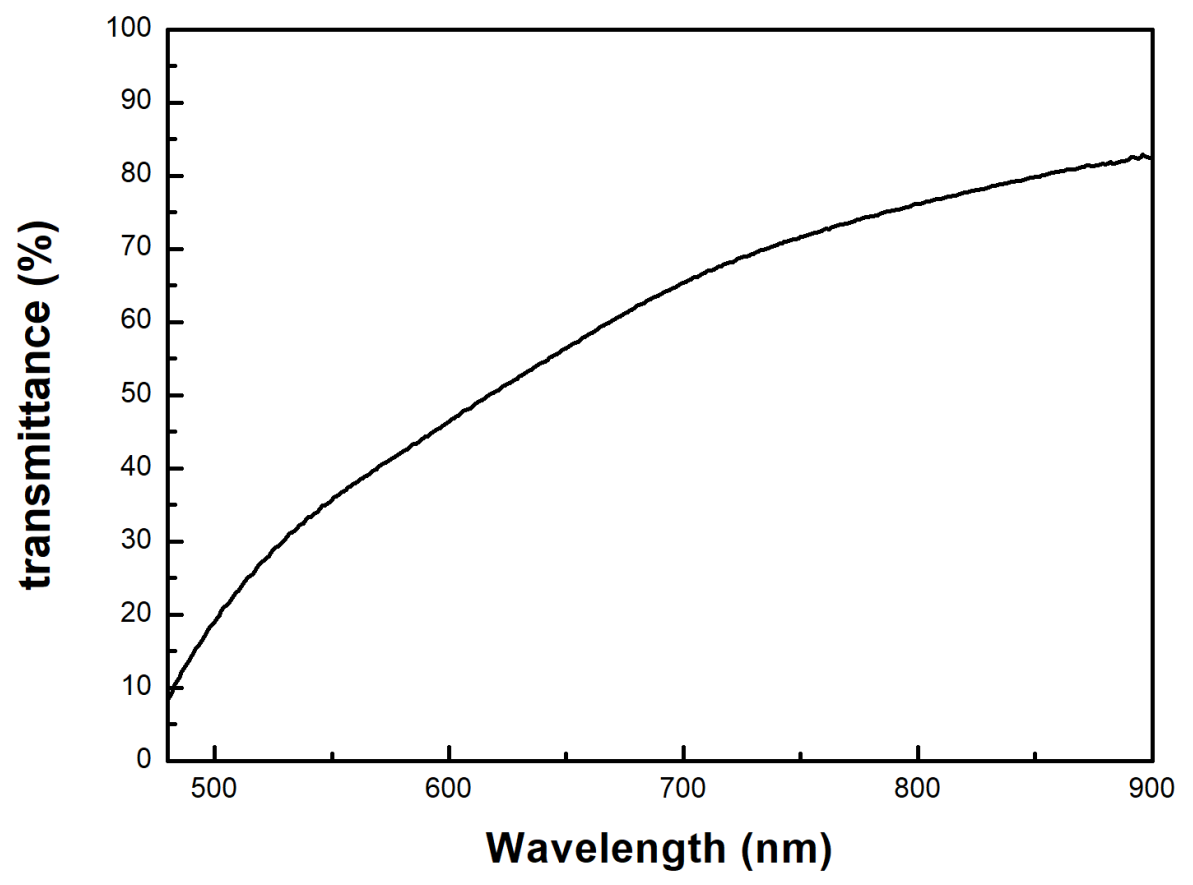

Figure S3. UV-vis spectrum of the stretched film.

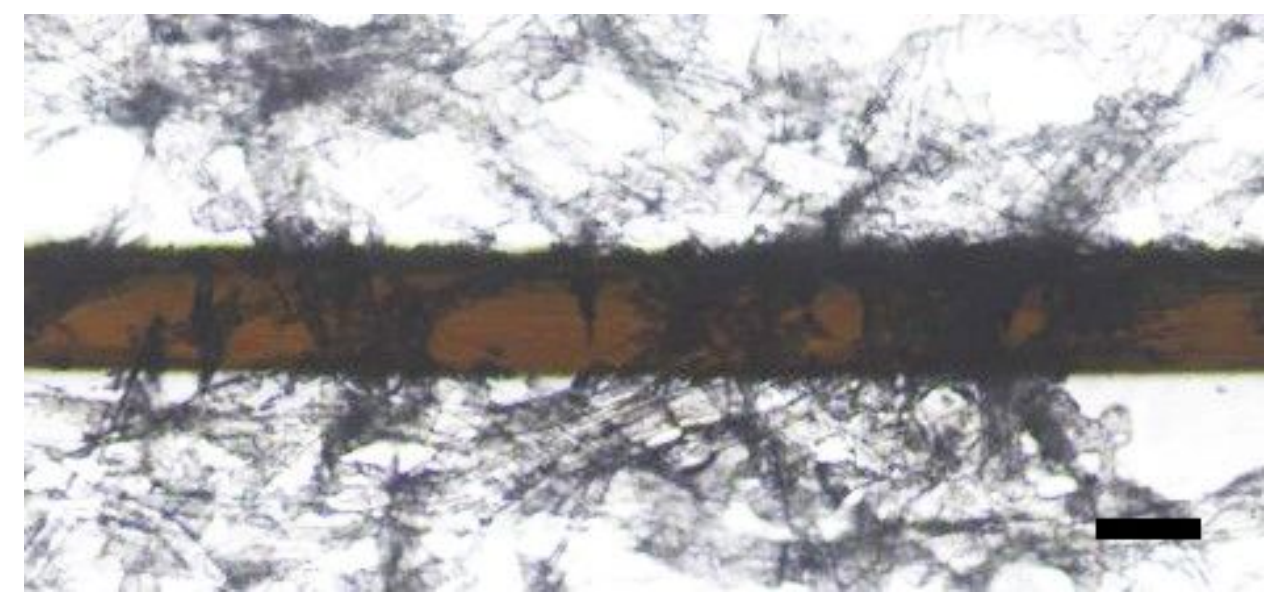

Figure S4. a) Optical microscopy image of the cross-section of PDA modified Nafion film which shows that both the surface and the bulk turn brown in color. Scale bar :100 $\mu \mathrm{m}$. 


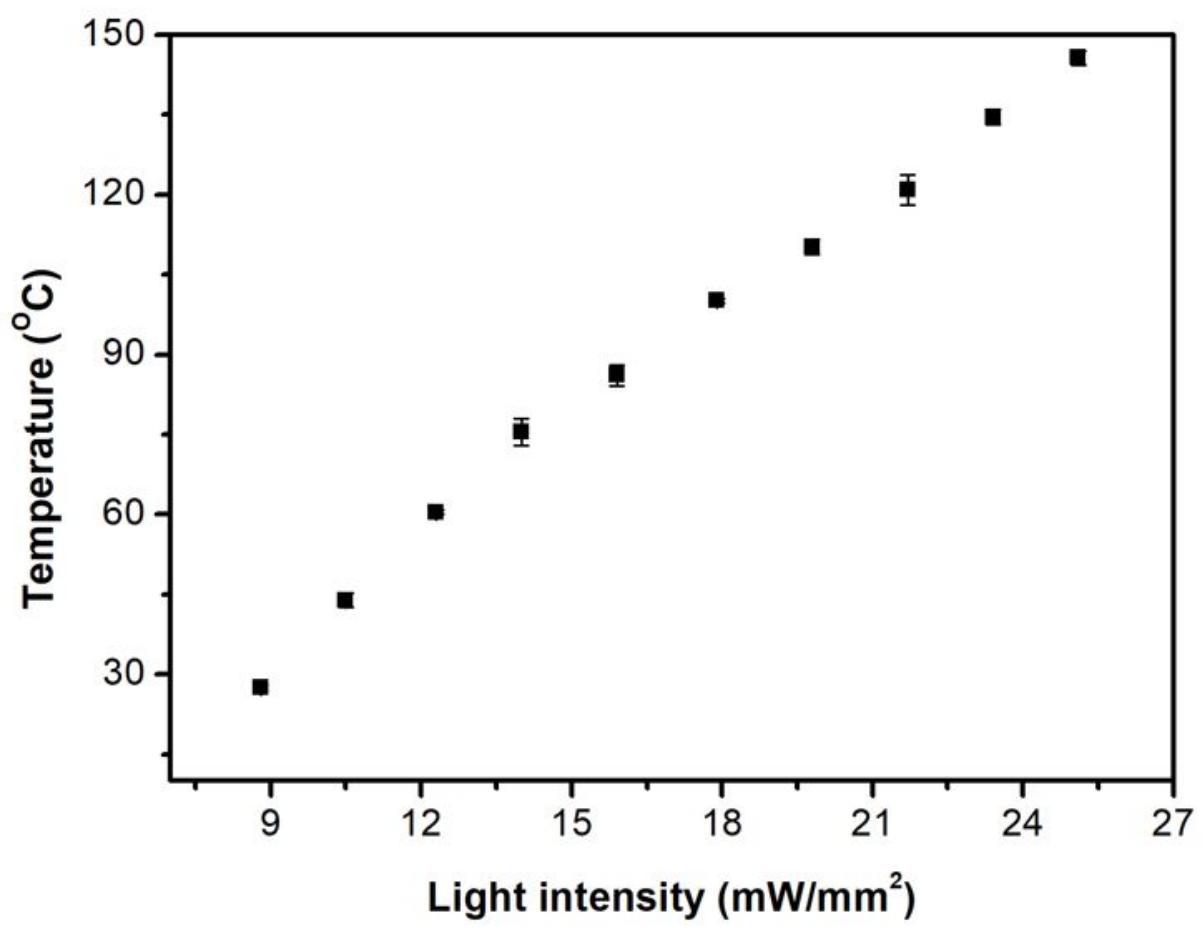

Figure S5. Equilibrium temperature with the intensity of NIR laser.
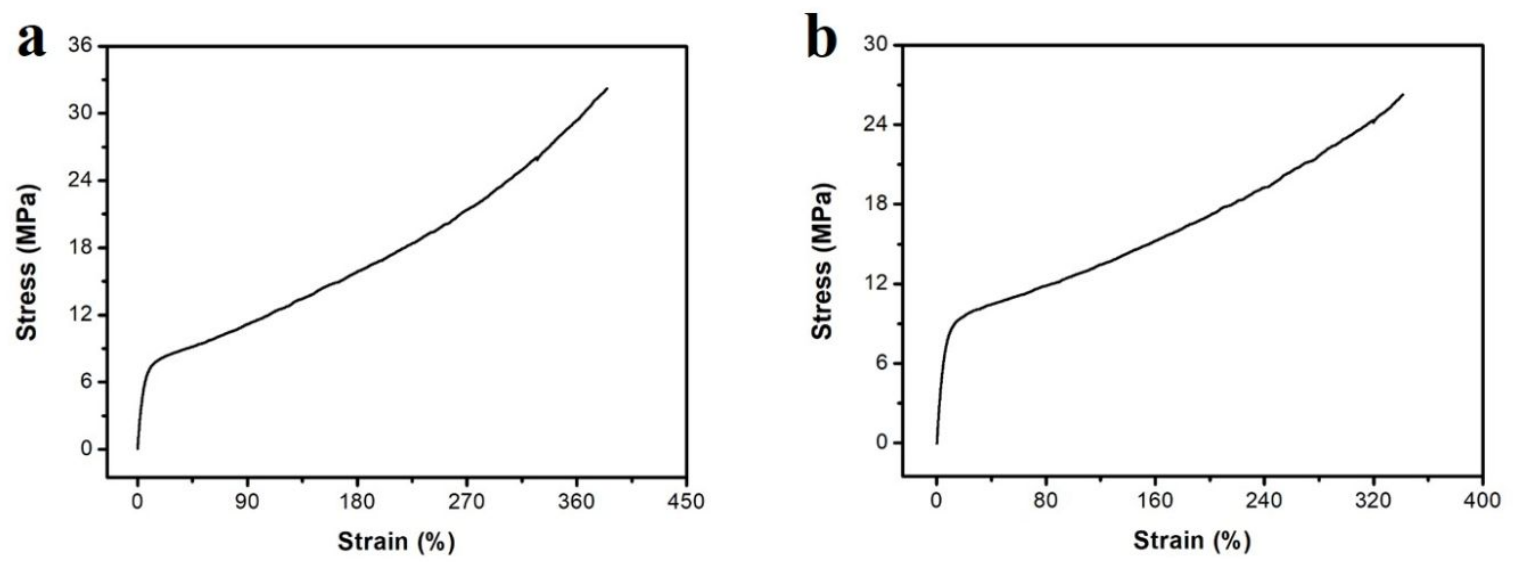

Figure S6. Elastic modulus and elongation at break of a) Nafion (elastic modulus $=99$ $\mathrm{MPa}$, elongation $=380 \%$ ) and $\mathrm{b}$ ) Nafion/PDA (elastic modulus $=108 \mathrm{MPa}$, elongation $=340 \%$ ). 


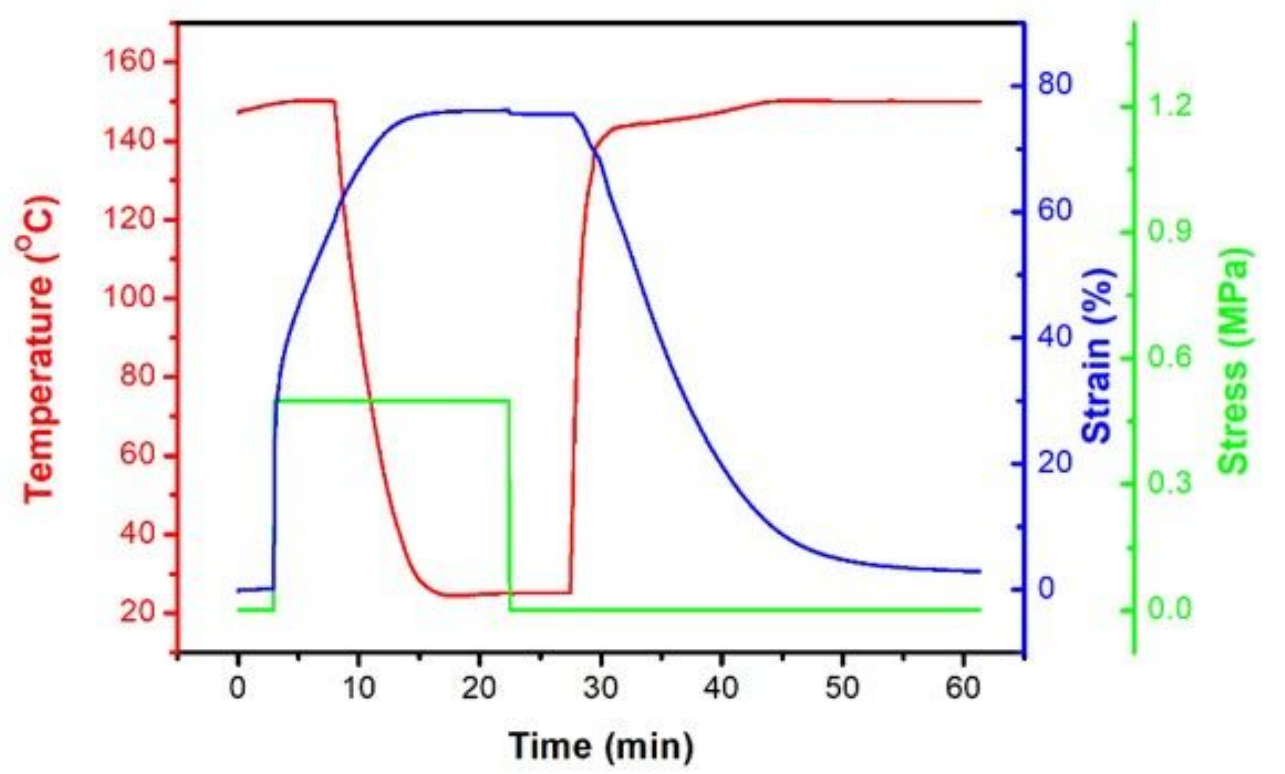

Figure S7. Shape recovery cycle of the PDA-modified Nafion film consisting of a shape-memory creation procedure and recovery under stress-free conditions. $R_{\mathrm{f}}: 98.5 \%$, $\mathrm{R}_{\mathrm{r}}: 97.1 \%\left(\mathrm{~T}_{\mathrm{d}}=150{ }^{\circ} \mathrm{C}, \mathrm{T}_{\mathrm{r}}=150{ }^{\circ} \mathrm{C}\right)$.
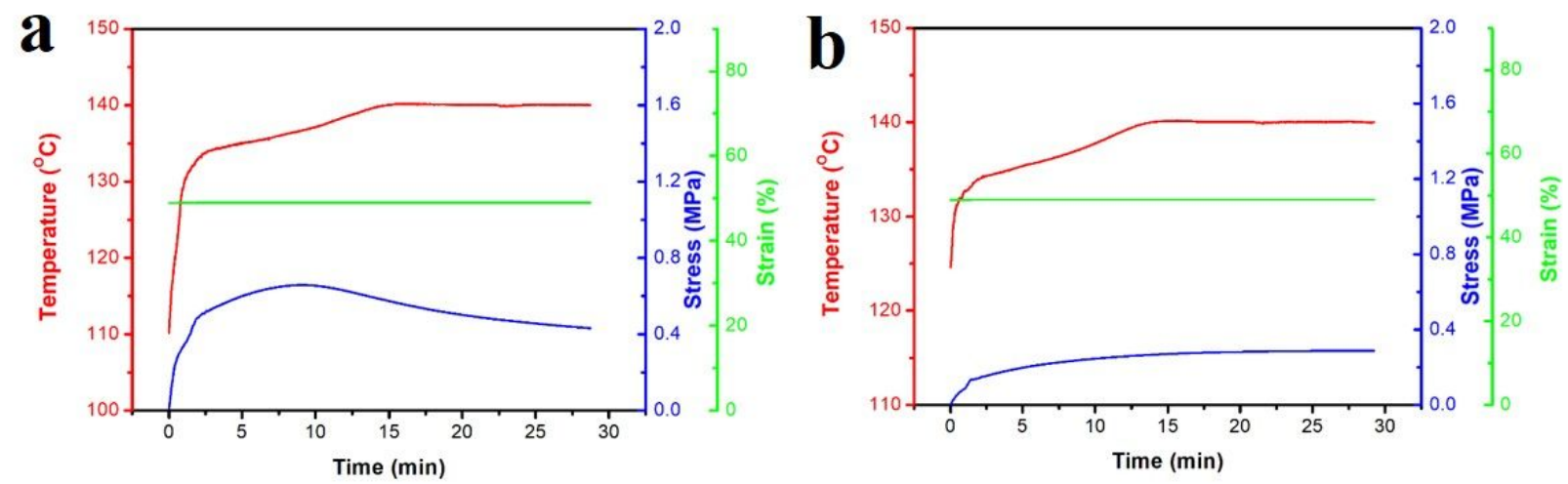

Figure S8. Shape recovery curves of composite films under iso-strain condition. a) Repersented the unirradiated region (stretched at $120{ }^{\circ} \mathrm{C}$, recovered at $140{ }^{\circ} \mathrm{C}$ ). b) Repersented the irradiated region (stretched at $160{ }^{\circ} \mathrm{C}$, recovered at $140{ }^{\circ} \mathrm{C}$ ). 

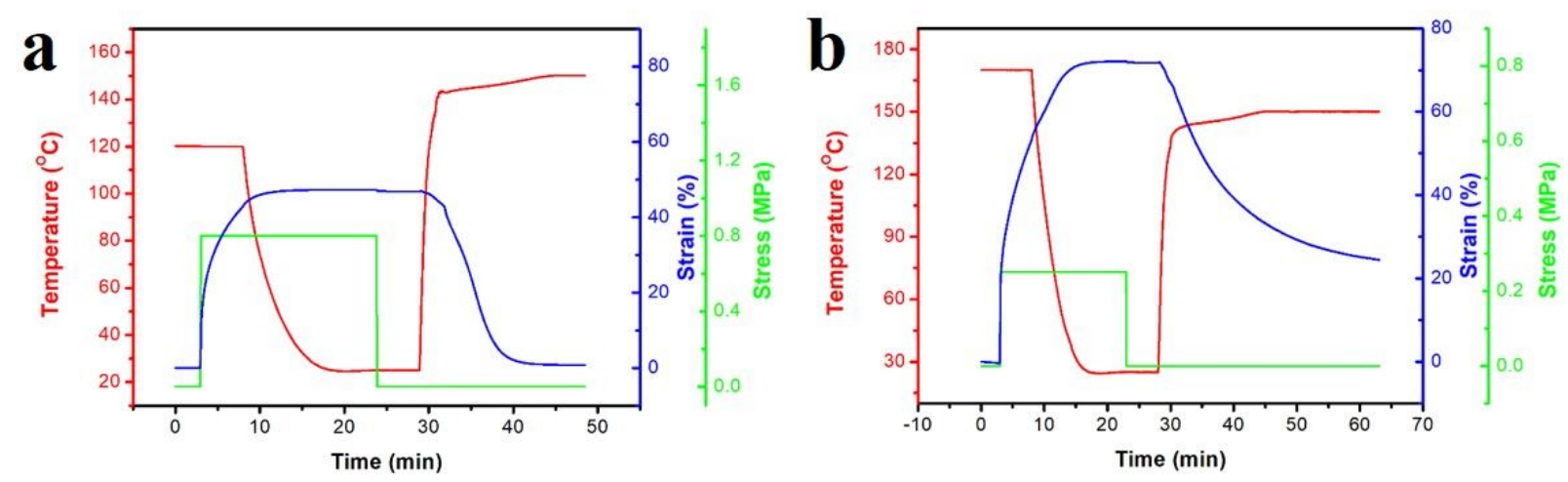

Figure S9. Shape recovery cycle of the Nafion/PDA film with different thermotemporal conditions under stress-free conditions. a) Repersented the unirradiated region (stretched at $120{ }^{\circ} \mathrm{C}$, recovered at $150{ }^{\circ} \mathrm{C}, \mathrm{R}_{\mathrm{f}}: 98.1 \%, \mathrm{R}_{\mathrm{r}}: 99.2 \%$ ). b) Repersented the irradiated region (stretched at $170{ }^{\circ} \mathrm{C}$, recovered at $150{ }^{\circ} \mathrm{C}, \mathrm{R}_{\mathrm{f}}: 98.7 \%, \mathrm{R}_{\mathrm{r}}$ : $75.4 \%)$.

$\mathbf{a}$
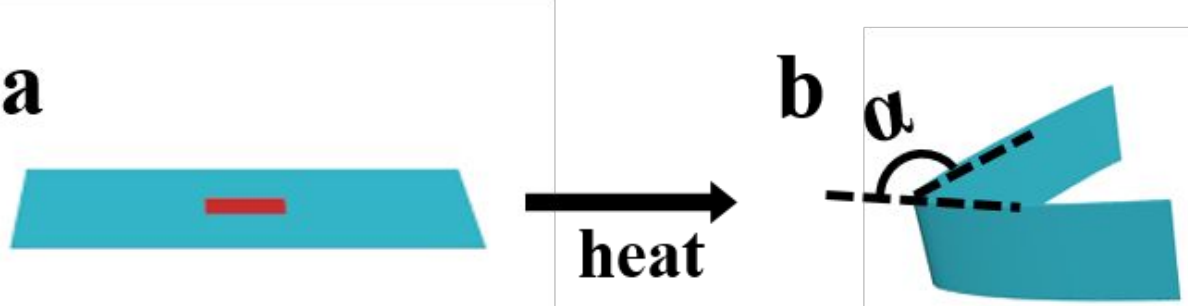

Figure S10. a) Schematic representation of the film with a single rectangular pattern by NIR laser. b) Schematic representation of the deformation after heating. 


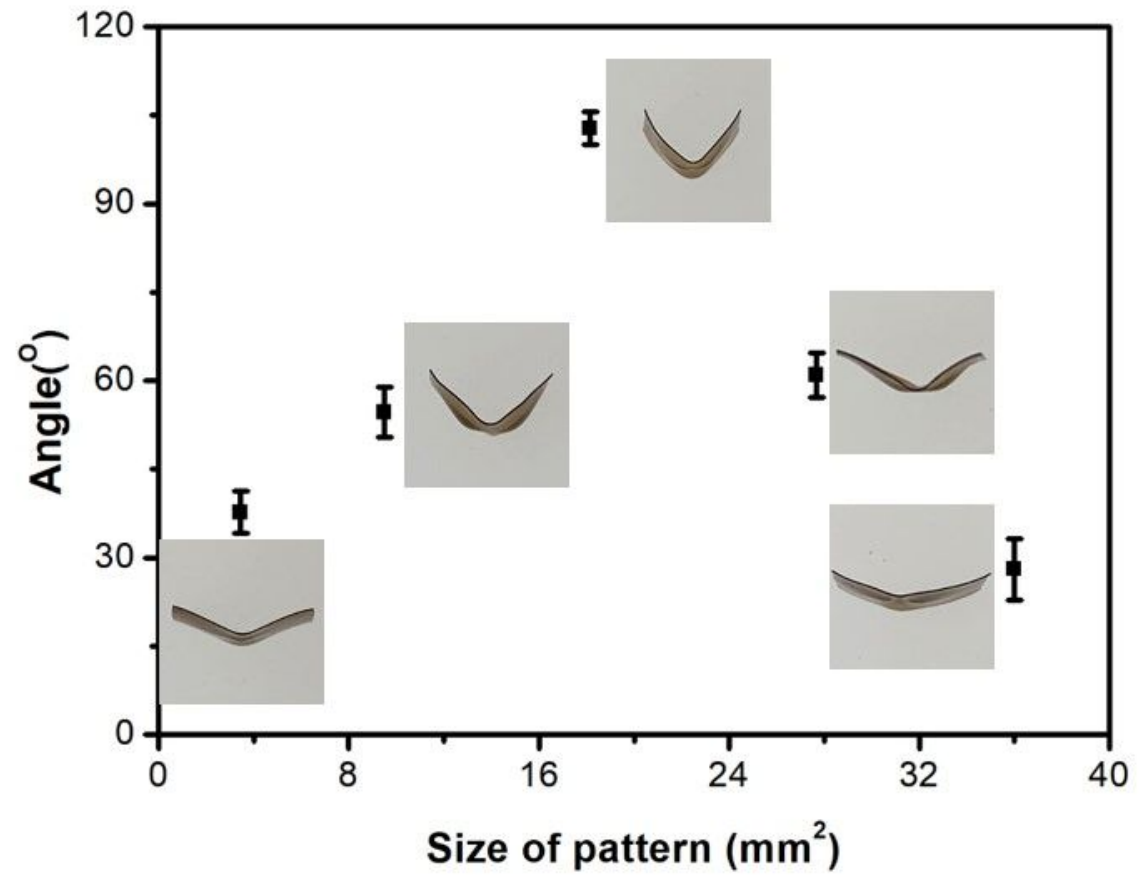

Figure S11. Graph of the influence of the size of illumination pattern on the magnitude of deformation. Size of patterns: $2.3 \mathrm{~mm} * 1.5 \mathrm{~mm}, 3.8 \mathrm{~mm} * 2.5 \mathrm{~mm}, 5.5 \mathrm{~mm} * 3.3 \mathrm{~mm}, 7.1$ $\mathrm{mm} * 3.9 \mathrm{~mm}, 8.0 \mathrm{~mm} * 4.5 \mathrm{~mm}$. 

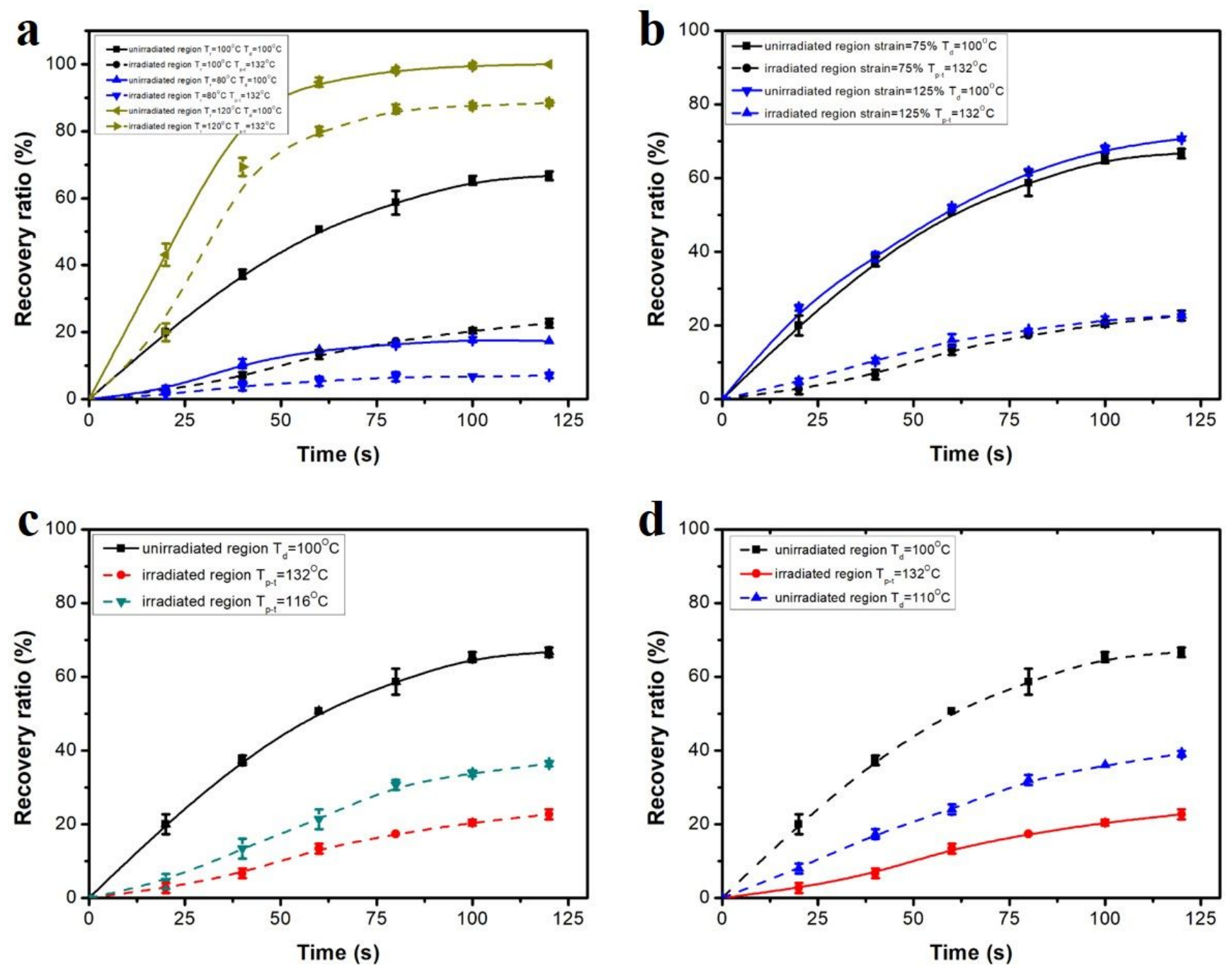

Figure S12. Graphs of the recovery ratio mismatch evolution under different regulatory factors. a) The mismatch evolution of distinct regions under differnet recovery temperatures. b) The mismatch evolution of distinct regions under differnet strain $\left(T_{r}\right.$ $=100{ }^{\circ} \mathrm{C}$ ). $\mathrm{c}$ ) The mismatch evolution of distinct regions under differnet photo-thermal temperatures $\left(\mathrm{T}_{\mathrm{r}}=100{ }^{\circ} \mathrm{C}\right.$, strain $\left.=75 \%\right)$. d) The mismatch evolution of distinct regions under differnet deforming temperatures $\left(\mathrm{T}_{\mathrm{r}}=100{ }^{\circ} \mathrm{C}\right.$, strain $\left.=75 \%\right)$. 

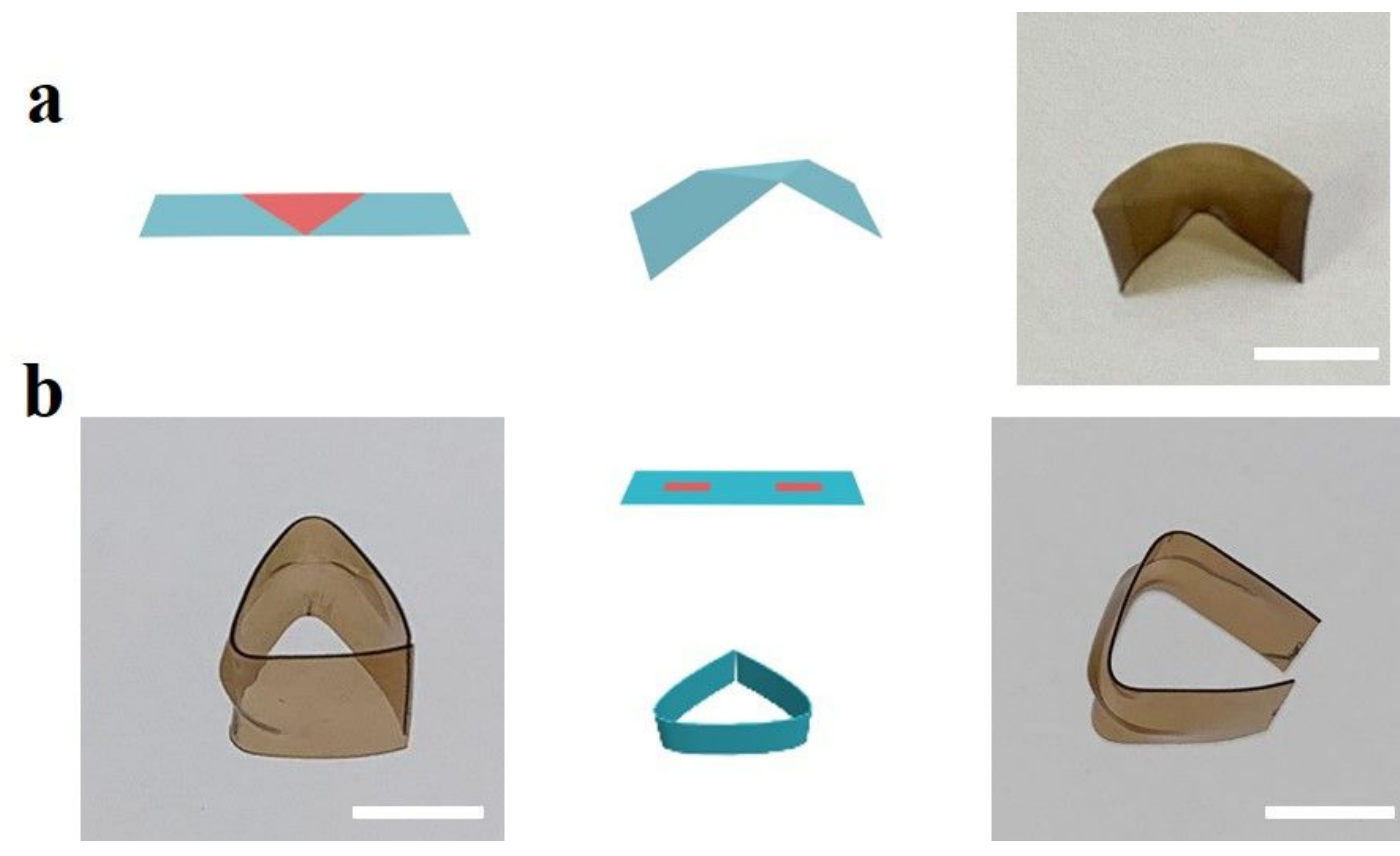

Figure S13. a) An us-filmwith an isosceles triangle pattern $(6.1 \mathrm{~mm} * 6.1 \mathrm{~mm})$ whose central axis was perpendicular to the stretching direction deformed to an inclined surface. b) The same geometric information encoded by two methods to obtain an equilateral triangle (left : by NIR illumination, right : by direct heating). Scale bar :0.5 $\mathrm{cm}$.
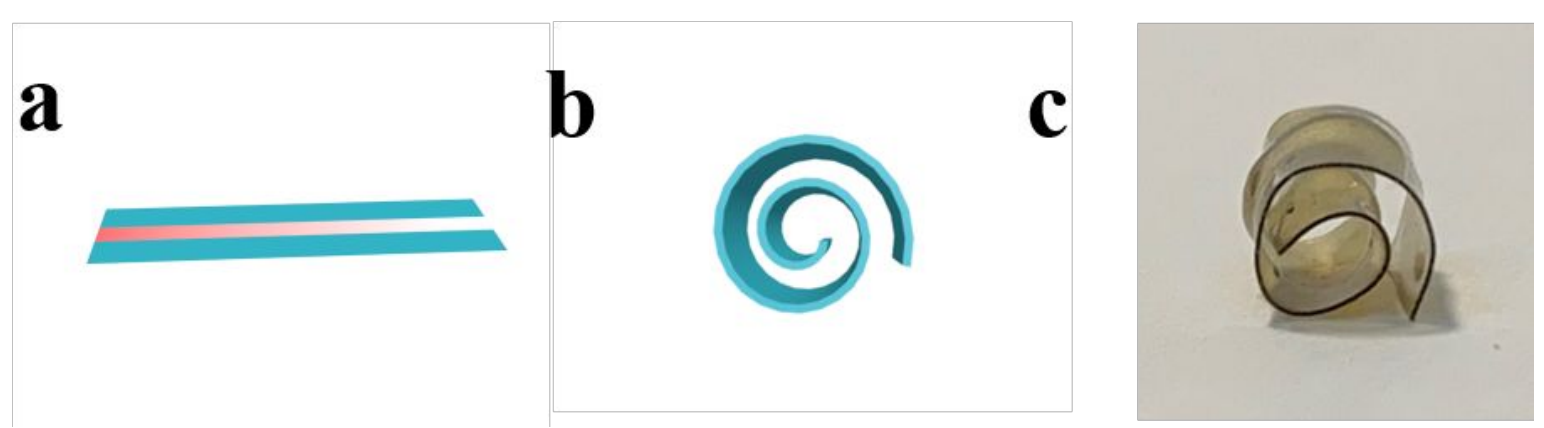

Figure S14. a) Schematic representation of an us-film with a gradual changed pattern (the size of pattern: $40.0 \mathrm{~mm} * 3.3 \mathrm{~mm}$, the size of unstretched film: $20.0 \mathrm{~mm} * 7.0 \mathrm{~mm}$ ).

b) Schematic representation of the films after deformation. c) Photograph of the film(stretched to strain $=100 \%$ at $100{ }^{\circ} \mathrm{C}$ ), which was patterned by NIR laser $\left(\mathrm{T}_{\mathrm{p}-\mathrm{t}}\right.$ changed from $108{ }^{\circ} \mathrm{C}$ to $148{ }^{\circ} \mathrm{C}, \mathrm{T}_{\mathrm{r}}=100{ }^{\circ} \mathrm{C}$ ). 


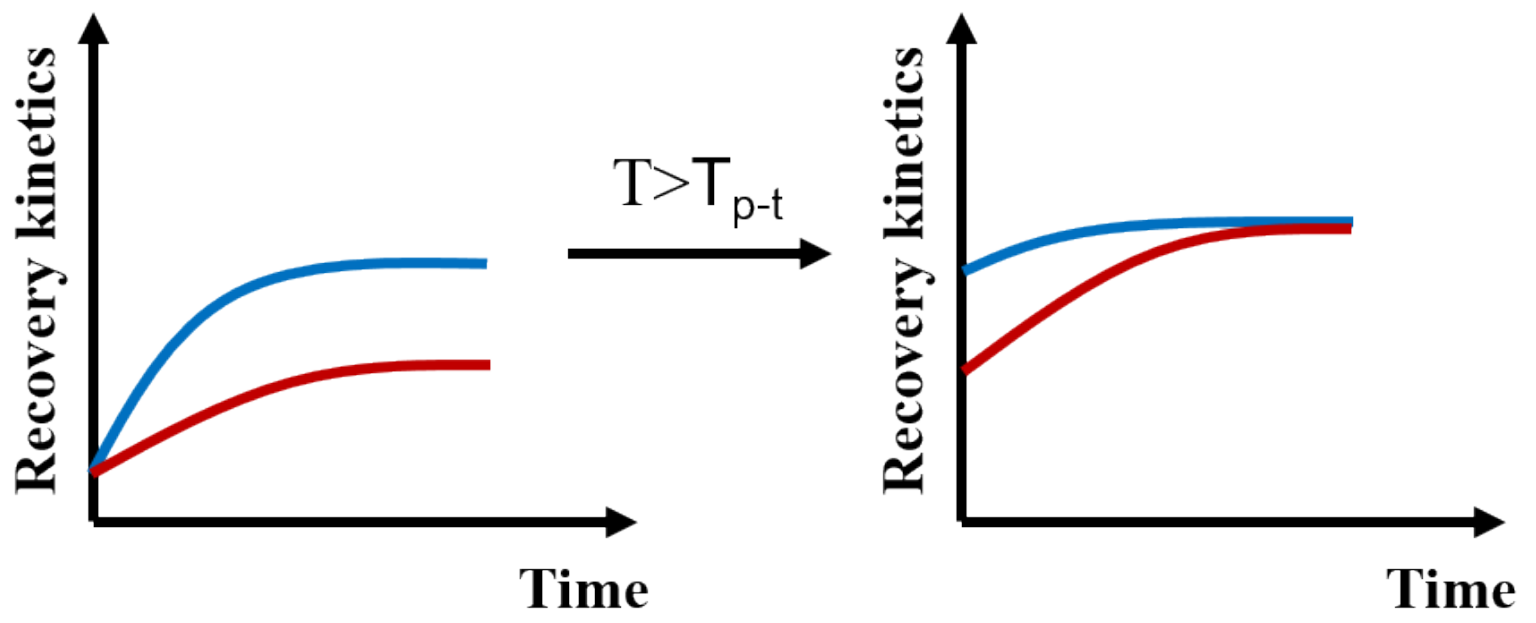

Figure S15. The different recovery kinetics between the irradiated regions and unirradiated regions was wiped when heating to a temperature higher than $\mathrm{T}_{\mathrm{p}-\mathrm{t}}$ (The blue curve represents the unirradiated region recovery kinetic curve, and the red curve represents the irradiated region recovery kinetic curve).
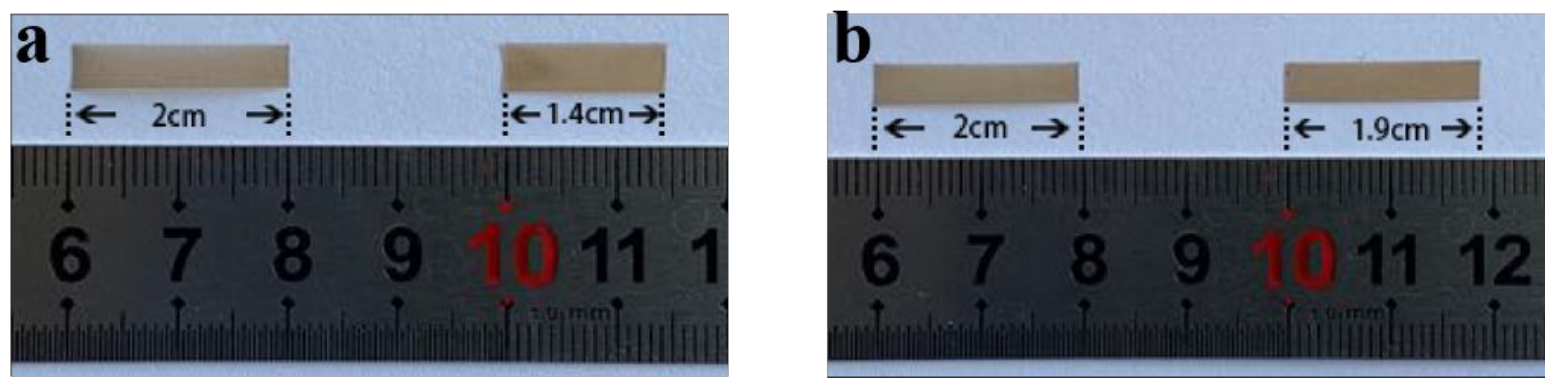

Figure S16. Shape recovery ratio of Nafion/PDA composite films with different $T_{d}$ in $37{ }^{\circ} \mathrm{C}$ water. a) Strain $=100 \%, \mathrm{~T}_{\mathrm{d}}=80{ }^{\circ} \mathrm{C}$. b) Strain $=100 \%, \mathrm{~T}_{\mathrm{d}}=170{ }^{\circ} \mathrm{C}$. 


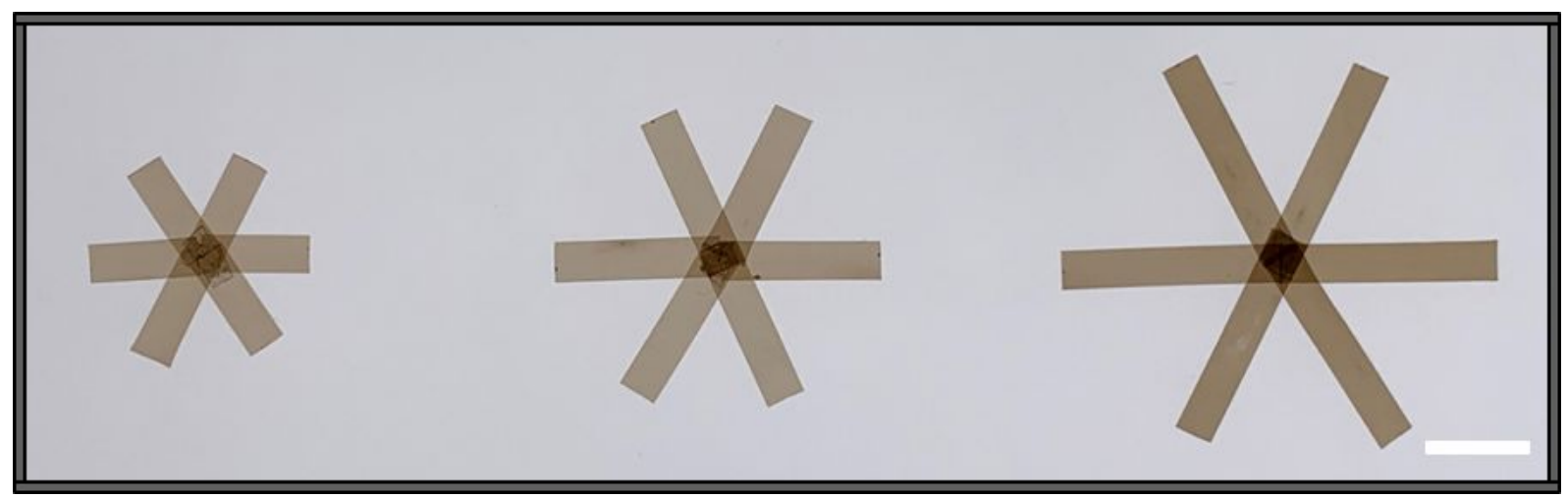

Figure S17. Three 2D materials constituted by strip composite films with different lengths of $1.0 \mathrm{~cm}, 1.5 \mathrm{~cm}, 2.0 \mathrm{~cm}$. Scale bars: $1 \mathrm{~cm}$

Table S1. Regular physical and chemical properties of Nafion and Nafion/PDA

\begin{tabular}{|c|c|c|}
\hline Properties & Nafion & Nafion/PDA \\
\hline $\begin{array}{c}\text { Photo-thermal conversion } \\
\text { capacity }\end{array}$ & none & good \\
\hline Elastic modulus & $99 \mathrm{MPa}$ & $108 \mathrm{MPa}$ \\
\hline Elongation at break & $380 \%$ & $340 \%$ \\
\hline $\mathrm{R}_{\mathrm{f}}\left(\mathrm{T}_{\mathrm{d}}=150{ }^{\circ} \mathrm{C}, \mathrm{T}_{\mathrm{r}}=150{ }^{\circ} \mathrm{C}\right)$ & $97.0 \%$ & $98.5 \%$ \\
\hline $\mathrm{R}_{\mathrm{r}}\left(\mathrm{T}_{\mathrm{d}}=150{ }^{\circ} \mathrm{C}, \mathrm{T}_{\mathrm{r}}=150{ }^{\circ} \mathrm{C}\right)$ & $97.0 \%$ & $97.1 \%$ \\
\hline$\alpha$ transition temperature & $55{ }^{\circ} \mathrm{C}-135{ }^{\circ} \mathrm{C}$ & $40{ }^{\circ} \mathrm{C}-180{ }^{\circ} \mathrm{C}$ \\
\hline Color & colorless & brown \\
\hline PDA distribution & $/$ & $\begin{array}{c}\text { on the surface and } \\
\text { inside of the film }\end{array}$ \\
\hline
\end{tabular}




\section{References}

[1] Chen, T. T.; Li, H.; Li, Z. H.; Jin, Q.; Ji, J. A "writing" strategy for shape transition with infinitely adjustable shaping sequences and in situ tunable 3D structures. Mater. Horiz. 2016, 3, 581-587. 